\title{
The versatility of Tricholepis glaberrima (Brahmadandi): An Overview
}

\author{
Khare E. 网, Ghosh S., Sharma A., Nayanika
}

Received: 08.06.2020

Revised: 09.08.2020

Accepted: 26.11.2020

\begin{abstract}
Since ancient times, crude drugs have been used as medicines and are of great importance for human beings. However, traditional knowledge about the use of medicinal plants is eroding day by day, and there was a need to document the everyday experience of these indigenous medicinal plants. Ayurveda describes the medicinal values and uses of plants for healthcare. By the course of time, various new plants got added to Ayurvedic material medica, Dravyaguna Vigyan. Tricholepis glaberrima (Brahmadandi) is one of them. This plant has great importance due to its nutritive value and a significant source of medicines as they have been found throughout human history.This plant is mostly used for its aphrodisiac property, but several unknown activities need to be taken seriously. This mini-review paper encompasses the Ayurvedic aspects as well as the phytochemistry structure and pharmacological activities of the Brahmadandi plant. The current review focuses on the updated information from various scientific studies and reports available in the context of the phytoconstituents and pharmacology of this plant. This review also provides adequate information about the use of this plant in an Indian system of medicine, Ayurveda.
\end{abstract}

Key Words: Ayurveda, Brahmadandi, Modern medicine, Medicinal uses, Phytochemistry, Pharmacological activity

\section{Introduction}

In the present scenario, plants have a great potential for producing new drugs as a traditional medicine to treat various types of diseases. Due to fewer side effects, the uses of these herbal medications are increased. Although there are many herbal plants available, yet no one knows about an important player which is known as Tricholepis glaberrima as "Brahmadandi" belongs to family Asteraceae which is the largest flowering plant family with 30,000 species and a little over 1,100 genera distributed throughout the world. Out of 30,000 species, there are around 900 species under 167 genera that have grown in India (Priyadarshi and Singh, 2018). Tricholepis is a Greek word meaning trichomes (hair) and lips, lepido scale. The name glaberrima is derived from a Latin 'glaber' which means bald. Brahmadandi is prominently used as an aphrodisiac. As per the ethnomedicinal survey, this plant is bitter, increases the appetite, stimulates liver as well as used as antiinflamatives, hypoglycemic, diuretic, antibacterial, antispasmodic. It acts as the best tonic to get rid of exhaustion. The Aerial part and bark of roots of

\section{Author's Address}

Department of Pharmaceutical Chemistry, Faculty of Pharmacy, ITM University, Gwalior (M.P.), India P.O. Box: 474001

E-mail.: ekta.sop@itmuniversity.ac.in
Brahmadandi are used for a further medicinal purpose (Khare, 2007). It is found around West Rajputana, Mount Abu, Central India, Konkan, Deccan and Western Ghat of Bombay administration, Hills of Mysore. It regularly develops on developed fields, rough soil of prairies. It is a yearly herb around $1 \mathrm{~m}$. in stature, greyish with purple bracts (Priyadarshi and Singh, 2018). It is an erect yearly spiked herb with short fanned stem, broadly spreading from the base. It develops to a tallness of 0.3 to $0.12 \mathrm{~m}$. Leaves are extrapolated, masterminded in a substitute structure. Leaves length is $7-12 \mathrm{~cm}$ since a long time ago, secured with cottony fleece underneath and prickly edge. The flaps are triangular and the spines are frequently $2.5 \mathrm{~cm}$ long. The head of leaves is $6.8 \mathrm{~mm}$ long, ovoid and glabrous. Blossoms are little and thin, less penciled. Flowerheads happen in lone round balls (globose), 3-5 cm over, bunched at the parts of the bargains. Petals of blossoms are $5 \mathrm{~mm}$ long. Blossoming happens among December and January. Previous contemplates have recognized a few natural properties of concentrates and disconnected mixes of the individual from this family (Deshpandey et al., 2014). 


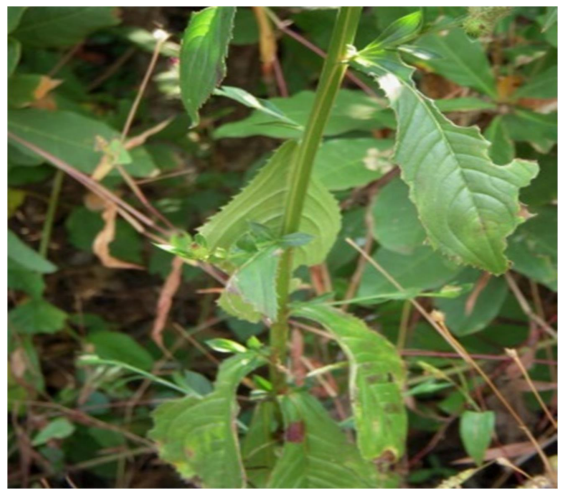

Figure1. Plant of Tricholepis glaberima (Source: Google )

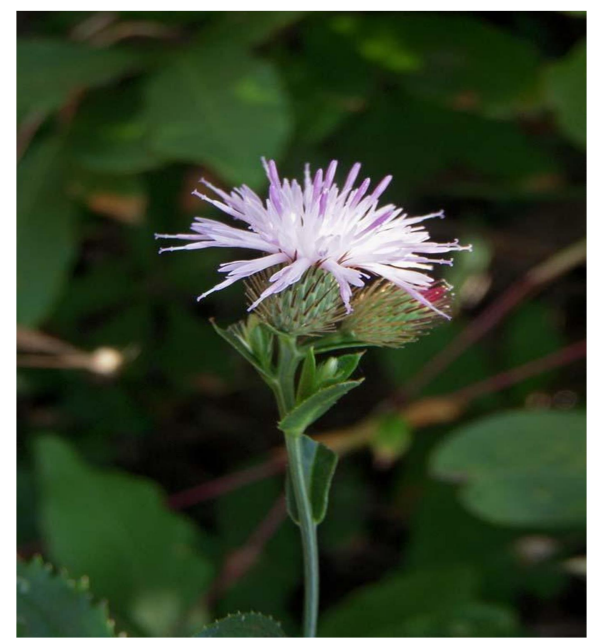

Figure 2. Flowering of Tricholepis glaberima (Source: Google)

\section{Pharmacological Property}

Different scientist have done their research work on brahmadandi plant with specific activity such as antidepressant activity, antifungal activity, antiinflammatory activity etc. by using etanolic extract of Tricholepis glaberima and in combination with various root extract (Shashi and Neetha, 2019; Somashekhar and Mishra, 2007; Yadava and Belwanshi, 2009).

\section{Antidepressant activity}

Melancholy is a hazardous ailment that is portrayed by negative considerations and sentiments of powerlessness. It is brought about by diminished degrees of Monoamines like noradrenaline, dopamine and serotonin in the mind. In like manner, the medications which can possibly decrease levels of Monoamines, first by hindering Monoamine oxidase compound, might be viable in the treatment and the board of despondency. The ethnobotanical study revealed the antidepressant movement of Tricholepis glaberrima in rodents because of the nearness of phytochemical constituents like alkaloids, flavonoids, and glycosides. The investigation was finished by two diverse test models of sorrow, for example, constrained swimming test and tail suspension test by taking standard medication imipramine with a portion of $10 \mathrm{mg} / \mathrm{kg}$ (Kiranmai et al., 2017). The outcome shows that the methanolic concentrate of flying pieces of Tricholepis glaberrima which contains compound constituents like alkaloids (ephedrine), flavonoids, and go about as reversible monoamine oxidase inhibitors. Thus, that improves the exercises of dopamine and serotonin in the mind by hindering the enzymatic breakdown of the cerebrum synthetic substances by monoamine oxidase hindrance and has stimulant like action (Padashetty and Mishra, 2008; Padashetty and Shrihari, 2007). Additionally, the pathophysiology incorporates the vehicle of both dopamine and serotonin antecedents into the cerebrum by expanding the porousness of the blood-mind hindrance to the forerunners and evoking the energizer potential. Alternately, the shortening of idleness time in the FST and TST predominantly relies upon the improvement of focal 5HT and catecholamine synapses. Subsequently, Tricholepis glaberrima elevated parts separate has a stimulant impact in creature models of melancholy (Manerikar and Kulkarni, 1978).

\section{Antifungal activity}

This study of Tricholepsis glaberrima was reported based on acetone and methanolic extraction of flowers under reduced pressure. The Betulin compound (Fig. 5) was tested against various fungi such as Trichoderma viride and Aspergillus niger at various concentrations. The area of growth inhibition was recorded at $27^{\circ} \mathrm{C}$ while the standard drug was griseofulvin (Yadava and Belwanshi, 2009).

\section{Anti-inflammatory activity}

The anti-inflammatory activity of the Brahmadandi is associated with the inhibition of the CycloOxygenase enzyme. One study reveals that due to the presence of phytochemical constituents such as alkaloids, flavonoids, glycosides, saponins it showed possible significant inhibitory action against prostaglandin. 


\section{Antioxidant activity}

Free radicals trigger a wide variety of chronic diseases. Inhuman body there is a relationship between the diet rich in antioxidants and the occurrence of the disease in human beings. From natural sources, antioxidant products are extremely significant in various diseases. One study reported that the ethanolic extract of Tricholepis glaberrima possesses high DPPH extremist rummaging action, and $\mathrm{H}_{2} \mathrm{O}_{2}$ revolutionary searching action because of the presence of phenolic compounds, showing that the higher the complete phenolic content better the free revolutionary searching movement (Chetan et al., 2012). Various solvents of leaves were accounted for to have superoxide anion searching movement by Nitro blue tetrazolium measure. All the concentrates displayed a most extreme level of free revolutionary rummaging at a dose of 200 $\mu \mathrm{g} / \mathrm{ml}$. The most noteworthy revolutionary rummaging movement was displayed by $\left.\mathrm{CH}_{3}\right)_{2} \mathrm{CO}$ extricate whose $\mathrm{IC}_{50}$ esteem was twofold to that of L-ascorbic corrosive (Abraham et al., 1986).

\section{a-amylase inhibitory activity}

One ethnobotanical study reported $\alpha$-amylase inhibitory activity of brahmadandi.In the study, $70 \%$ Hydroethanolic extract of polyherbal formulation, containing leaves of Argemone mexicana, roots of Echinopse chinatus, and aerial parts of Tricholepis glaberrima were investigated for its potential to inhibit the $\alpha$-amylase enzyme. For the evaluation of the $\alpha$-amylase enzyme inhibiting potential of a polyherbal formulation, $70 \%$ hydroethanolic extract was subjected under study (Qureshi et al., 2017). For invitro $\alpha$-amylase inhibition assay, the formulation was tested for activity in four concentrations. The highest amylase inhibition of $74.67 \%$ was observed at $25 \mathrm{mg} / \mathrm{ml}$ concentration of the extract. It has been concluded from the results that the use of this formulation will be beneficial in reducing the digestion rate and absorption of carbohydrates. This can be effective in the treatment of diabetes. This study indicates the antidiabetic potential in Tricholepis glaberrima (Rwanda et al., 2004).

\section{Aphrodisiac activity}

One ethnobotanical study announced a sexual enhancer movement of Tricholepsis glaberrima, having the property to build the sex hormones. A test study was finished by utilizing a methanolic concentrate of the Tricholepis glaberrima plant, which was infused in explicitly dynamic rodents. The impact of this investigation was assessed. Coming about Tricholepsis glaberrima goes under the Spanish fly class which helps in the incitement of the creation of the semen and aides in the expanding pace of the sexual hormones (Singhal et al., 1982). There are two cancer prevention agent catalysts, catalase and superoxide dismutase in testicular homogenate just as on testicular histology were additionally evaluated. The methanolic concentrate of flying pieces of Tricholepis glaberrima was controlled at the portion of $200 \mathrm{mg} / \mathrm{kg}$ b.w for 28 days which adjusted the different segments of the sexual conduct concentrate fundamentally. It expanded the intromission inertness (IL) and mounting dormancy (ML) altogether. The testicular histology proposed that the concentrate upgrades the expansion of seminiferous epithelium which thusly favors spermatogenesis. Consequently, discoveries give exploratory proof that the concentrate of Tricholepis glaberrima has Spanish fly properties and an expansion in the bodyweight of Tricholepsis glaberrima rewarded rodents because of the androgenic properties which include the nearness of anabolic action (Agrawal et al., 1986).

Consequently, in the condition when there is an instance of lessened prostatic emission related with male barrenness the Tricholepis glaberrima may fill in as a compelling device. The wellbeing of sperm relies on the status of cancer prevention agents present in the body. The outcome was seen that in the testicular homogenate of the rodents had a huge increment in the movement of two amazing cell reinforcement catalysts, catalase and superoxide dismutase when contrasted with the control rats. These chemicals may assist with holding the motility of the sperm successfully by killing the injurious impacts of the ROS. This may help in improving the achievement pace of rewarding male fruitlessness (Padashetty and Mishra, 2007).

Definitively this article demonstrates the potential estimation of Tricholepis glaberrima as a remedial specialist in rewarding male fruitlessness. It can upgrade sexual movement in typical rodents and favors spermatogenesis by improving the multiplication of seminiferous epithelium. The plant Tricholepis glaberrima was credited to fall under the space of aphrodisiacs which increment 
the sexual want and those that improve the quality and animate the creation of semen. (Chittam and Deore, 2012)

\section{Phytochemical constituents}

This plant shows its pharmacological activity because of its chemical constituents which are the following:

- Spinasterol

- Stigmasterol

- Betulin

- Triterpenoid-cycloart-23-en-3-beta,25-diol

- 5,2'-dihydroxy-3,6,7-tri-methoxy flavone5-O-a-L-rhamno-pyranosyl-xylopyranosylD-galactopyranoside

Spinasterol (Fig. 3) is a phytosterol found in a variety of plant sources such as spinach and other green vegetables. Due to spinach, it is given the name of spinasterol. The chemical was recently found in Gordonia ceylanica.

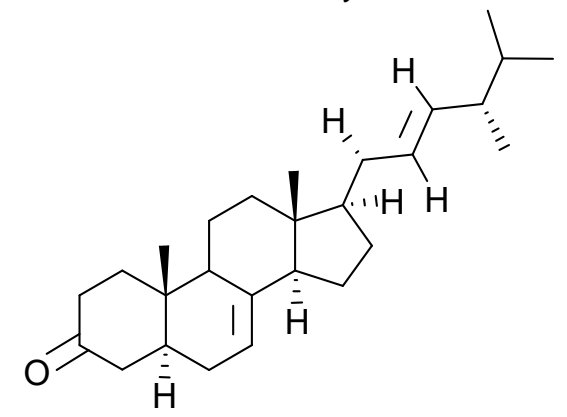

Figure 3. Spinasterol

Stigmasterol (Fig. 4) is a phytosterol that is derived from plants. As a food additive, phytosterols have cholesterol-lowering properties and may act in cancer prevention.

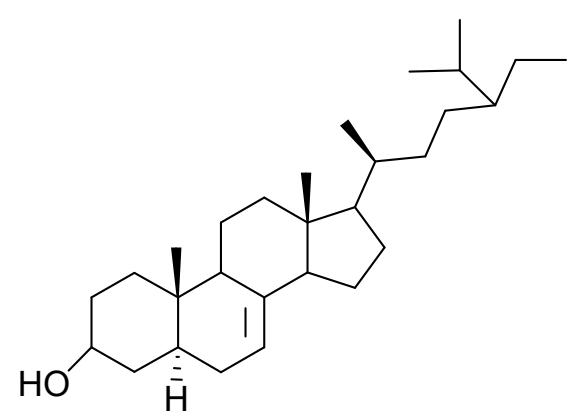

Figure 4. Stigmasterol

Betulin (Fig. 5) is a naturally occurring triterpene. It is commonly isolated from the bark of birch trees.<smiles>CC(C)[C@H]1C[C@H](CO)[C@@H]2CC[C@H]1C1CCC3C(C)(C)C(O)CC[C@@]3(C)[C@]1(C)CC2</smiles>

Figure 5. Betulin

Cycloart-23-en-3-beta,25-diol (Fig. 6) is a triterpenoid.It acts as a metabolite and is a vital constituent of Brahmadandi.<smiles></smiles>

Figure 6. Cycloart-23-en-3-beta,25-diol

5,2-dihydroxy-3,6,7-tri-methoxy-flavone-5-O-Lrhamnopyranosyl-xylopyranosyl-D

galactopyranoside (Fig. 7) is a new flavone glycoside isolated from the methanolic extract of flower of pant. It shows good antifungal activity.

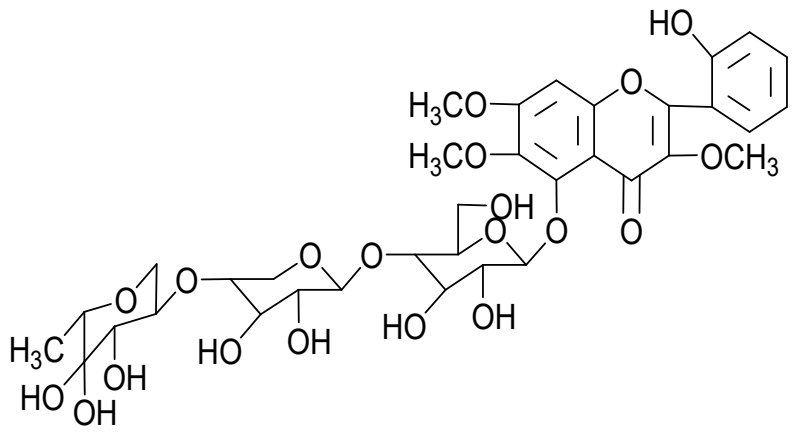

Figure7. 5,2-dihydroxy-3,6,7-tri-methoxyflavone-5-O-L-rhamnopyranosyl-xylopyranosylD galactopyranoside

With the commercialization of herbal medicines it has become necessary to undertake systematic studies on their quality, safety and efficacy levels. There are various manners by which nations characterize therapeutic plants or spices or items 
got from them, and have embraced different ways to deal with permitting, administering, assembling and exchanging to guarantee their wellbeing, quality and adequacy (Saikat and Chakraborty, 2019).

Regardless of the utilization of natural prescriptions over numerous hundreds of years, just a generally modest number of plant species has been read for conceivable clinical applications. Wellbeing and adequacy information are accessible for a considerably more modest number of plants, their concentrates and dynamic fixings and arrangements containing them issues in normalization emerge from the mind boggling substance organization of natural medications. Normalization as far as certain marker mixes of a natural medication when all is said in done doesn't fill the need of normalization, since movement of the medication doesn't rely on one or a couple of compound parts. In a large portion of cases, it is the aftereffect of deliberate action of a few dynamic mixes just as of idle going with substances (Yoganarasimhan, 2000).

'Brahmadandi', commonly available and sold in different markets of India consists of the roots of Echinops echinatus (Compositae) at one place, on the other hand in some place aerial parts of Tricholepis glaberrima (Compositae) are supplied. The drug is popular as an aphrodisiac and used in the treatment of male infertility. However convincing scientific data to ensure its identity, quality, safety and efficacy are still unavailable.

Keeping in see the broad utilization of Brahmadandi and its questionable nature it was proposed to embrace, first, the methodical examinations on both the plants, so as to advance certain boundaries for their normalization and also, to explore upon their organic exercises in order to legitimize their customary cases. The examinations performed are depicted in four parts comprising of:

1. Introduction, current status of the traditional medicine, importance of standardization, selection of the plants and their profile, and the research envisaged.

2. Development of the standardization parameters for the selected plants.

3. Evaluation of the selected plants for the biological activity.

4. Identification and quantification of compounds from the bioactive fraction using HPTLC.
Accordingly phytochemical normalization utilizing complex logical procedures alongside appraisal of its action is important to guarantee quality and adequacy of home grown medications and this should be possible at two levels

(1) Standardization by concoction/biomarker compound examination and normalization by unique finger impression methods/chemoprofiling

(2) Standardization by appraisal of the foreseen action.

Natural compounds are easily obtainable. Hence, in future it can replace synthetic derivatives effectively. Beneifts are like free from toxicity, needed in little quantity and obtainable at fewer prices in contrast to synthetic derivatives. Pharmacological studies may be a hint to investigate use of herbals as therapeutic agents. Hence, this may be useful to discover safer substitute. Future work can be done by isolating its main chemical constituents which are responsible for its activity and elucidating its mechanism of action.

\section{Conclusion}

The characteristic item assumes a pivotal job in the improvement of chemotherapeutic medications. They give critical impact without upsetting other sub-frameworks though current medication influences a few metabolic exercises in the human framework and has symptoms, which makes the body progressively powerless to another malady. There has been expanding enthusiasm for ethnomedicine all through the world as of late. In this smaller than normal survey, different phytochemical and pharmacological examinations of one plant have been accounted for. In any case, there is as yet a shortage of data on other natural properties of this plant. As far as we could possibly know, inhibitory activity against chemicals related with constant illnesses has not been concentrated to date. This survey gives precise data about the concerned plant, which may end up being valuable for scientists and the advancement of the conventional information on therapeutic plants.

\section{Acknowledgment}

The authors are thankful to I.T.M. University, Gwalior, (M.P.) India for sustained encouragement, meticulous supervision to carry out work. 


\section{Khare et al.}

\section{References}

Abraham, Z., Bhakuni, S. D., Garg, H. S., Goel, A. K., Mehrotra, B. N. and Patnaik, G. K. 1986. Screening of Indian plants for biological activity Part XII. Indian Journal of Experimental Biology, 24: 48-68.

Agarwal, S., Chauhan, S. and Mathur, R. 1986. Antifertility effect of emblin in male rats. Andrologia, 18: 125-131.

Chetan, J., Sampathkumar, K. K., Shailsekhar and Prakash, H. S. 2012. Antioxidant, antibacterial and DNA protectingactivity of selected medicinally important Asteraceae plants. International Journal of Pharmacy andPharmaceutical Sciences, 4(2): 257-261.

Chittam, K. P. and Deore, S. L. 2012. Pharmacognosy of Tricholepis glaberrima: A review. International Journal of Pharmaceutics, 3: 1-8.

Deshpandey, M., Kumar, V. C. and Yadav, R. C. 2014. morphological work in Two Endemic Species of Tricholepis (Asteraceae) in India.Cytologia, 79(4): 561566.

Kiranmai, G., Veena, R. and Afreen, S. 2017. Pharmcological screening of antidepressant activity of plant Tricholepis glaberrima. European Journal of Biomedical and Pharmaceutical sciences, 4(12): 634-639.

Khare, C. P. 2007. Indian medicinal plants: An illustrated dictionary Springer, Berlin, Heidelberg, New York , 671678.

Manerikar, S. V. and Kulkarni, A. B. 1978. Chemical investigation of Tricholepis glaberrima. Indian Journal of Chemistry, 16: 439-440.

Padashetty, S. A. and Mishra, S. H. 2008. Phytochemical and pharmacognostical parameters for standardization of Tricholepis glaberrima: A medicinal herb. Journal of Medicinal and Aromatic Plants Scioence, 30(4): 381-388.

Padashetty, S. and Shrihari, H. M. 2007. An HPTLC Method for the Evaluation of Two Medicinal PlantsCommercially Available in the Indian Market Under the Common Trade Name Brahmadandi. Chromatographia, 66(5): 447-449.
Priyadarshi, A. and Singh, S. 2018. Review on Ayurvedic, Pharmacognostical, Phytochemical and Pharmacological insights of Brahmadandi (Tricholepis glaberrima). International Journal of Research and Analytical Reviews, 5(2): 1738-1747.

Padashetty, S. A. and Mishra, S. H. 2007. Aphrodisiac Studies of Tricholepis glaberrima with Supportive Action from Antioxidant Enzymes. Pharmaceutical Biology, 45(7): 580-586.

Qureshi, A. S., Khaja, P. and Sumia, F. 2017. In vitro assay of alpha amylase inhibitory activity of polyherbal formulation. World Journal of Pharmacy and Pharmaceutical sciences, 6(12): 1089-1093.

Rwanda, S., Abu, S., lmad, I. H., Fatma, U. and Afifi, 2004. Alpha-amylase inhibitory activity of some plant extracts with hypoglycemic activity. Scientia Pharmaceutica, 72: 25-33.

Shashi, K. and Neetha, C. S. 2019. Evaluation of antidepressant activity of Tricholepis glaberrima bark alone and in combination. National journal of physiology, pharmacy and pharmacology, 9(8): 775-779.

Saikat and Chakraborty, R. 2019. Herbal medicine in India, Springer publication.

Somashekhar, A. P., and Mishra, S. H. 2007. Aphrodisiac studies of Tricholepis glaberrima with supportive action from antioxidant enzymes. Pharmaceutical Biology, 45 (7): 1-7. 2 .

Singhal, A., Pritish, C., Sharma, R. P. and Werner, H. 1982. Guaianolides from Tricholepis glaberrima. Phytochemistry, 21(2): 462-463.

Yoganarasimhan, S. N. 2000. Medicinal Plants of India vol.1: Tamil Nadu, Bangalore Cybermedia, 263.

Yadava, R. N. and Belwanshi, P. 2009. New antifungal constituents form the Tricholepis glaberrima DC. Asian Journal of Chemistry, 2(1): 6683-6688. 